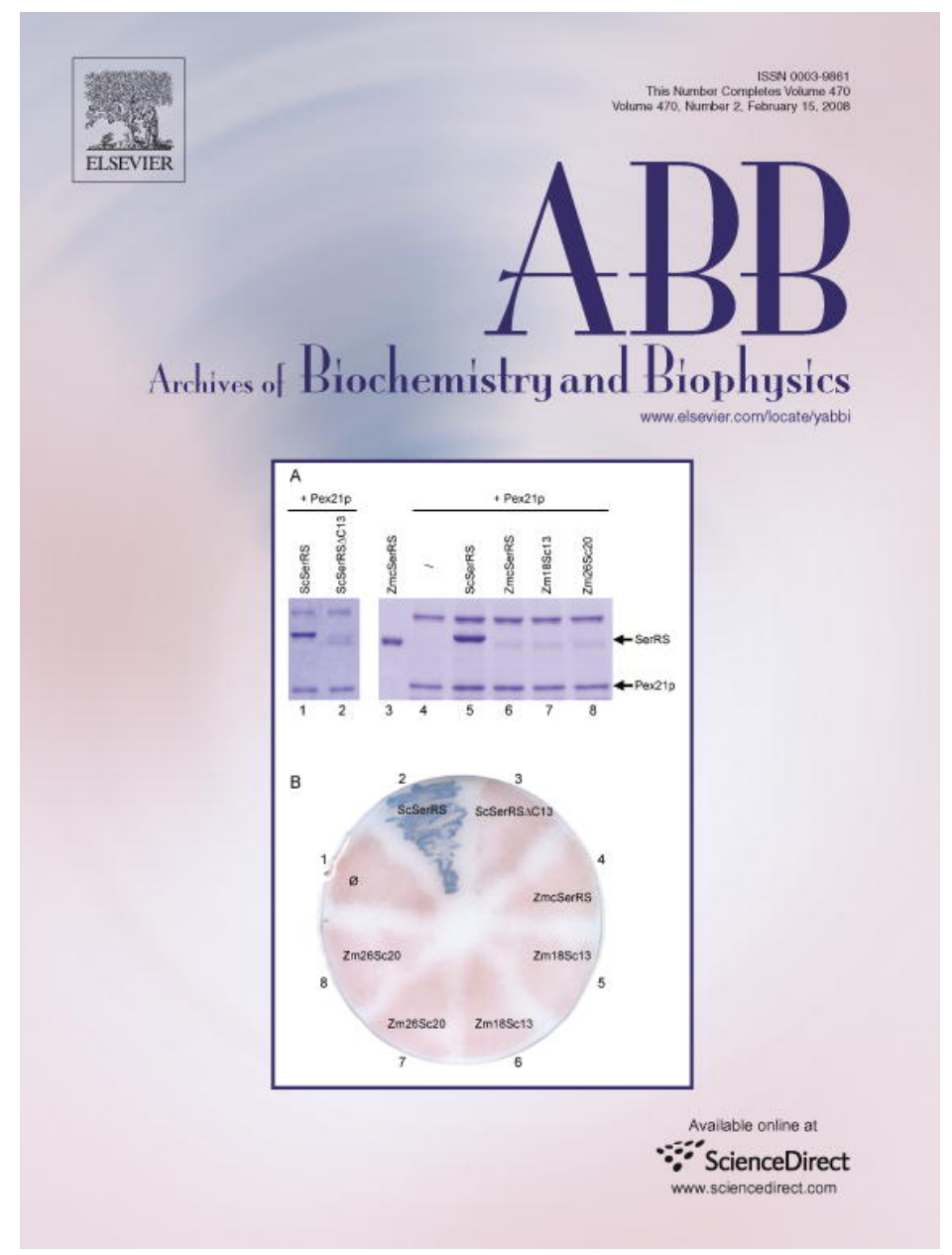

This article was published in an Elsevier journal. The attached copy

is furnished to the author for non-commercial research and education use, including for instruction at the author's institution, sharing with colleagues and providing to institution administration.

Other uses, including reproduction and distribution, or selling or licensing copies, or posting to personal, institutional or third party websites are prohibited.

In most cases authors are permitted to post their version of the article (e.g. in Word or Tex form) to their personal website or institutional repository. Authors requiring further information regarding Elsevier's archiving and manuscript policies are encouraged to visit: 


\title{
Monosialylated biantennary $N$-glycoforms containing GalNAc-GlcNAc antennae predominate when human EPO is expressed in goat milk
}

\author{
R. Montesino ${ }^{\text {a }}$, J.R. Toledo ${ }^{\mathrm{b}}$, O. Sánchez ${ }^{\mathrm{b}}$, A. Sánchez ${ }^{\mathrm{c}}$, D.J. Harvey ${ }^{\mathrm{d}, \mathrm{e}}$, L. Royle ${ }^{\mathrm{e}}$, \\ R.A. Dwek ${ }^{\text {d }}$, P.M. Rudd ${ }^{\text {e }}$, G.J. Gerwig ${ }^{\text {f }}$, J.P. Kamerling ${ }^{\text {f }}$, J.A. Cremata ${ }^{\text {a,* }}$ \\ a Department of Carbohydrate Chemistry, Center for Genetic Engineering and Biotechnology, P.O. Box 6162, Havana 10600, Cuba \\ ${ }^{\mathrm{b}}$ Department of Animal Biotechnology, Center for Genetic Engineering and Biotechnology, P.O. Box 6162, Havana 10600, Cuba \\ ${ }^{c}$ Department of Proteomics, Center for Genetic Engineering and Biotechnology, P.O. Box 6162, Havana 10600, Cuba \\ d Oxford Glycobiology Institute, University of Oxford, South Parks Road, Oxford, UK \\ e Dublin-Oxford Glycobiology Laboratory, National Institute for Bioprocessing Research and Training, Conway Institute, \\ University College Dublin, Dublin, Ireland \\ ${ }^{\mathrm{f}}$ Bijvoet Center, Department of Bio-Organic Chemistry, Utrecht University, Utrecht, The Netherlands
}

Received 1 October 2007, and in revised form 27 November 2007

Available online 5 December 2007

\begin{abstract}
Recently, our group reported the expression of recombinant human erythropoietin in goat milk (rhEPO-milk) as well as in the mammary epithelial cell line GMGE (EPO-GMGE) by cell culture using the adenoviral transduction system. $N$-Glycosylation characterization of rhEPO-milk by Normal-Phase HPLC profiling of the fluorophore, 4-aminobenzoic acid-labeled enzymatically released $N$-glycan pool from rhEPO-goat milk, combined with MALDI, ESI-MS and LC/MS, revealed that low branched, core-fucosylated, $N$-glycans predominate. The labeled $N$-glycans were separated into neutral and charged fractions by anion exchange chromatography and the charged $N$-glycans were found to be mostly $\alpha 2,6$-monosialylated with Neu5Ac or Neu5Gc in a ratio of 1:1. Unlike the $N$-glycans from rhEPO produced in $\mathrm{CHO}$ cells, where the glycans are multiantennary highly sialylated, core-fucosylated oligosaccahrides, or even in the goat mammary gland epithelial cell line cultured in vitro in which multiantennary, core- and outer-arm fucosylated, monosialylated $N$ glycans are the most abundant species, a large proportion of the $N$-glycans from rhEPO-milk were monosialylated, biantennary, antennae mostly terminating with the more unusual GalNAc-GlcNAc motive and without outer-arm fucosylation. These findings, emphasizing the difference in the $N$-glycan repertoire between the rhEPO-milk and EPO-GMGE, are consistent with the principle that glycosylation is cell-type dependent and that the cell environment is crucial as well.
\end{abstract}

(C) 2007 Elsevier Inc. All rights reserved.

Keywords: Mammary gland; Epithelial cells; Goat milk; Erythropoietin; Glycosylation; Sialylation; Monosialylated biantennary $N$-glycans

The large-scale production of recombinant biopharmaceutical glycoproteins in the milk of transgenic animals is becoming more widespread due to the very promising economic production processes [1]. To date several proteins have been expressed in the milk of transgenic animals in quantities ranging from a few micrograms to several grams

\footnotetext{
${ }^{*}$ Corresponding author. Fax: +5372714764.

E-mail address: jose.cremata@cigb.edu.cu (J.A. Cremata).
}

per liter. Some examples are: human lactoferrin in mice [2] and cows [3]; $\alpha 1$-antitrypsin [4] and $\mathrm{C1}$ inhibitor [5] in rabbits; human anti-thrombin [6] and human tissue-type plasminogen activator $[7,8]$ in goats; human Factor VIII [9] and human Protein $C$ [10] in pigs; human $\alpha$-glucosidase in mice [11] and rabbits [12] and human erythropoietin in rabbits [13] and pigs [14]. However, the functionality and specificity of mammary gland glycosylation is, as yet, incompletely understood in comparison with other mammalian cell lines. 
Human erythropoietin (hEPO) is a glycoprotein hormone with three potential $N$-glycosylation sites at Asn-24, -38, and -83, and one $O$-glycosylation site at Ser-126. The glycosylation on hEPO is essential for in vivo activity [15], as the unglycosylated hormone shows full in vitro but no in vivo biological activity [16]. Thus, the system for the production of biologically active EPO requires the biosynthetic machinery of mammalian cells like Chinese hamster ovary $(\mathrm{CHO})^{1}$ cell cultures, able to assemble the necessary tetrasialylated tetraantennary $N$-glycans to maintain the half life of the protein $[17,18]$.

Recently, our group has expressed hEPO in the milk of mice and goats (Capra hircus) by adenoviral transduction of the mammary secretory epithelial cells $[19,20]$. An adenoviral vector, carrying the hEPO cDNA, allowed the expression of the recombinant glycoprotein at levels over $2 \mathrm{~g} / \mathrm{L}$ in goat milk. However, the milk-derived recombinant hormone (rhEPO-milk), showed a lower molecular weight, more basic isoforms and a very low in vivo hematopoietic activity compared to the described homologous rhEPO produced in $\mathrm{CHO}$ cell cultures, presumably due to differences in the glycosylation of rhEPO produced in milk compared to that produced in $\mathrm{CHO}$ cell line [20]. Moreover, we have also established a continuous, non-transformed epithelial cell line (GMGE) from primary culture of goat mammary gland and expressed rhEPO in this system (EPO-GMGE). The recombinant protein expressed in GMGE cells showed an $N$-glycosylation pattern that significantly differed from that of the classical CHO-EPO, with core- and outer-arm fucosylation and low sialic acid content. The glycoprotein showed a reduced hematopoietic activity [21].

The aim of the present study was to characterize the $\mathrm{N}$ glycosylation of hEPO, as a glycoprotein model, expressed in the milk of goats to compare with that already reported for the same glycoprotein expressed in vitro in the goat epithelial mammary cell line, GMGE and the classical $\mathrm{CHO}$ cells system.

\footnotetext{
${ }^{1}$ Abbreviations used: 4ABA, 4-aminobenzoic acid; BHK, baby hamster kidney; $\mathrm{CHO}$, Chinese hamster ovary; GMGE, goat mammary gland epithelium; DEAE, diethylaminoethyl; dHex (deoxy-hexose (fucose); DHB, dihydroxybenzoic acid; DMB, 1,2-diamino-4,5-methylene-dioxybenzene; DSA, Datura stramonium lectin; EPO, erythropoietin; ESI, electrospray ionization; Fuc, fucose; Gal, galactose; GalNAc, $N$-acetylgalactosamine; GlcNAc, $N$-acetylglucosamine; GNA, Galanthus nivalis lectin; h, human; Hex, hexose; HexNAc, $N$-acetyl-hexose; HPLC, highperformance liquid chromatography; HRP, horseradish peroxidase; LC/ MS, Liquid chromatography-mass spectrometry; MAA, Maackia amurensis lectin; mAb, monoclonal antibody; MALDI, matrix-assisted laser desorption/ionization; MS, mass spectrometry; $\mathrm{m} / \mathrm{z}$, mass to charge ratio; NBT, nitro blue tetrazolium; Neu5Ac, $N$-acetylneuraminic acid; Neu5Gc, $N$-glycoylneuraminic acid; NP, normal-phase, NP-40, Nonidet P-40; PAGE, polyacrylamide gel electrophoresis; PNGase, peptide- $N^{4}-(N$ acetyl- $\beta$-D-glucosaminyl) asparagine amidase; $\mathrm{Q}$, quadrupole; rh, recombinant human; SDS, sodium dodecylsulfate; SNA, Sambucus nigra lectin; TFA, trifluoroacetic acid; TIC, total ion current; TOF, time-of-flight.
}

\section{Materials and methods}

\section{Production of EPO in goat milk}

rhEPO was expressed in goat milk by adenoviral transduction and purified from the skimmed milk pool from three nuliparous 1-year-old Toggenburg goats milked on days 32-38 after the induction of lactation [20]. The purity was greater than $99 \%$ as judged by sodium dodecyl sulfate-polyacrylamide gel electrophoresis (SDS-PAGE) with silver staining.

\section{SDS-PAGE and Western-blotting assay}

SDS-PAGE analysis was performed as described by Laemmli [22] in $12 \%$ polyacrylamide gels. Proteins were transferred to nitrocellulose filters (Schleicher and Schuell, Dassel, Germany) using a semidry electroblotter. After incubation with a monoclonal antibody $(\mathrm{mAb})$ antiEPO-horseradish peroxidase (HRP), conjugated signals were visualized with the $3,3^{\prime}$ diaminobenzidine tetrahydrochloride detection reagent (Sigma, St. Louis, MO).

\section{In vivo hematopoietic activity}

The rhEPO hematopoietic activity was evaluated by the increase of reticulocyte numbers in $\mathrm{B} 6 \mathrm{D} 2 \mathrm{~F} 1$ mice. At least six mice per experimental group were used. Mice were subcutaneously injected with 8,10 or $12 \mu \mathrm{g}$ of rhEPO samples. Four days post-injection, blood samples were collected and diluted with brilliant cresyl blue $(1 \%, \mathrm{v} / \mathrm{v})$ for reticulocyte counts. Ten fields per sample were counted. The relative hematopoietic activity of the inoculated dose was analyzed by regression for each sample using the $0 \mu \mathrm{g}$ dose as the baseline control. Biological activity in milk-derived hEPO was analyzed by ANOVA comparing the effect of the three dose levels and the baseline control.

\section{Proteolytic digestion and mass spectrometry analysis}

$N$-Deglycosylated protein $(50 \mu \mathrm{g})$ was digested with sequencing-grade trypsin (Promega, MA) at an enzyme/substrate ratio of $1 / 50$ at $37^{\circ} \mathrm{C}$ for $4 \mathrm{~h}$. Digestions were stopped by adding aqueous trifluoroacetic acid (TFA) $(1 \%, v / v)$. The proteolytic digest was separated by liquid chromatography (AKTA Basic, Amersham Pharmacia Biotech, Sweden) equipped with a splitter (LC-Packings, Netherlands) in a $0.3 \times 100 \mathrm{~mm}$ PepMap column (LC-Packings, Netherlands). The column was equilibrated in solvent A $\left(\mathrm{H}_{2} \mathrm{O}, 0.05 \%\right.$ TFA) and the digest was eluted with a linear gradient of Solvent A and solvent B (acetonitrile, $0.05 \%$ TFA) from 0 to $80 \%$ over $100 \mathrm{~min}$.

\section{Mass spectrometric analysis of peptides}

A hybrid quadrupole orthogonal acceleration tandem mass spectrometer (QTOF-2) from Micromass (Manchester, UK) fitted with a Zspray nanoflow electrospray (ESI) ion source was connected online with the HPLC system described above. The mass spectrometer was operated with a source temperature of $80^{\circ} \mathrm{C}$ and a drying gas flow of $50 \mathrm{~L} / \mathrm{h}$. The capillary and cone voltages were 3500 and $35 \mathrm{~V}$, respectively. To acquire the liquid chromatography-mass spectrometric (LC/MS) and LC-MS/MS spectra, the first quadrupole was used to select automatically the precursor ion within a window of 4-5 Th. Argon was used as the collision gas. Data acquisition and processing were performed using a MassLynx system (version 3.5). The mass accuracy was below $100 \mathrm{ppm}$.

\section{Oligosaccharide identification using lectin binding assays}

The "DIG Glycans Differentiation Kit" (Roche, Germany) was used to identify specific carbohydrate motives. After separation on $12 \%$ SDSPAGE, the glycoproteins $(1 \mu \mathrm{g}$ each) were bound to Immobilon membranes (Millipore, USA). The membranes were incubated at $25^{\circ} \mathrm{C}$ for $1 \mathrm{~h}$ 
with specific lectins that were digoxigenin-labeled. Afterwards, the filters were immersed in a solution containing polyclonal anti-digoxigenin antibody conjugated with alkaline phosphatase for another hour. The staining reaction was carried out in nitro blue tetrazolium (NBT)/X-phosphate solution without shaking.

\section{$N$-Glycans releasing, fluorophore labeling and normal-phase (NP) HPLC separation}

rhEPO from goat milk was enzymatically deglycosylated with peptide$N^{4}$-( $N$-acetyl- $\beta$-D-glucosaminyl) asparagine amidase (PNGase F) and the $N$-glycans recovered as described elsewhere [20,21]. Lyophilized oligosaccharides were labeled with $4 \mathrm{ABA}$ and resolved on a TSK Amide- 80 column $4.6 \times 250 \mathrm{~mm}$; TosoHaas, Japan) [23].

\section{Anion-exchange (diethylaminoethyl, DEAE) HPLC}

4ABA-labeled oligosaccharides were separated into neutral and acidic fractions on a BioSep-DEAE-PEI column $(7.6 \times 100 \mathrm{~mm}$; Phenomenex, San Juan, Puerto Rico). The mobile phase consisted of a gradient, formed from a solution of $20 \%(\mathrm{v} / \mathrm{v})$ acetonitrile in $10 \mathrm{mmol} / \mathrm{L}$ ammonium acetate, $\mathrm{pH} 6.5$ (solvent A), and a solution of $20 \%(\mathrm{v} / \mathrm{v})$ acetonitrile in $250 \mathrm{mmol} / \mathrm{L}$ ammonium hydroxide (solvent B). The flow rate was $0.8 \mathrm{~mL} /$ min and fluorescence detection was carried out using an excitation wavelength of $290 \mathrm{~nm}$ and emission wavelength of $355 \mathrm{~nm}$.

\section{Determination of $\mathrm{N}$-acetyl-and $\mathrm{N}$-glycolylneuraminic acid}

Neuraminic acids were released by hydrolysis in $2 \mathrm{M}$ acetic acid at $80^{\circ} \mathrm{C}$ for $3 \mathrm{~h}(50 \mu \mathrm{g} \mathrm{EPO} / 200 \mu \mathrm{L})$ and converted into fluorescent derivatives with 1,2-diamino-4,5-methylene-dioxybenzene (DMB). Briefly, $200 \mu \mathrm{l}$ of DMB solution $(7 \mathrm{mM}$, containing $1.4 \mathrm{M}$ acetic acid, $0.75 \mathrm{mM} \beta$ mercaptoethanol and $18 \mathrm{mM}$ sodium dithionite) was added to $200 \mu \mathrm{L}$ hydrolysate and then heated at $50^{\circ} \mathrm{C}$ for $2.5 \mathrm{~h}$ in the dark. After cooling on ice, $10-20 \mu \mathrm{L}$ was used for HPLC analysis. HPLC analysis was carried out on a reversed-phase C-18 column $(255 \times 46 \mathrm{~mm}$, Phenomenex, USA). The fluorescence detection was carried out using an excitation wavelength $373 \mathrm{~nm}$ and emission wavelength of $448 \mathrm{~nm}$. Elution was performed using acetonitrile:methanol:water $(9: 7: 84, \mathrm{v} / \mathrm{v} / \mathrm{v})$ at a flow rate of $1 \mathrm{~mL} / \mathrm{min}$.

\section{Mass spectrometry of the 4ABA-labeled $N$-glycans}

Matrix-assisted laser desorption/ionization time-of-flight (MALDITOF) mass spectrometry

Positive ion MALDI-TOF mass spectra were recorded with a Micromass TofSpec 2E reflectron-TOF mass spectrometer (Micromass, Manchester, UK) fitted with delayed extraction and a nitrogen laser $(337 \mathrm{~nm})$. The acceleration voltage was $20 \mathrm{kV}$; the pulse voltage was $3200 \mathrm{~V}$; and the delay for the delayed extraction ion source was $500 \mathrm{~ns}$. Samples were prepared by adding $0.5 \mu \mathrm{L}$ of an aqueous solution of the sample to the matrix solution $(0.3 \mu \mathrm{L}$ of a saturated solution of 2,5-dihydroxybenzoic acid (DHB) in acetonitrile) on the stainless steel target plate and allowing it to dry at room temperature. The sample/matrix mixture was then recrystallized from ethanol.

\section{Electrospray mass spectrometry (ESI-MS)}

Nano-electrospray mass spectrometry was performed with a WatersMicromass quadrupole-time-of-flight (Q-Tof) Ultima Global instrument. Samples in 1/1 (v/v) methanol:water were infused through Proxeon (Proxeon Biosystems, Odense, Denmark) nanospray capillaries. The ion source conditions were: temperature, $120^{\circ} \mathrm{C}$; nitrogen flow $50 \mathrm{~L} / \mathrm{h}$; infusion needle potential, $1.2 \mathrm{kV}$; cone voltage $100 \mathrm{~V}$; RF-1 voltage $180 \mathrm{~V}$. Spectra ( $2 \mathrm{~s}$ scans) were acquired with a digitization rate of $4 \mathrm{GHz}$ and accumulated until a satisfactory signal:noise ratio had been obtained. Masses were measured to $0.1 \mathrm{Da}$.

\section{Negative ion MS/MS}

Negative ion MS/MS data were recorded with the Waters-Micromass Q-Tof Ultima Global mass spectrometer as above. For MS/MS data acquisition, the parent ion was selected at low resolution (about 3 Th mass window) with the collision cell voltage set appropriately for the mass of the parent ion; typical values were $70-120 \mathrm{~V}$ for singly charged and 20 $50 \mathrm{~V}$ for doubly charged ions. Other voltages were as recommended by the manufacturer. Argon was used as the collision gas. Instrument control, data acquisition and processing were performed with a MassLynx data system (Version 4).

\section{$L C$-electrospray ionization (ESI) $M S$}

Glycans were analyzed using an LC Packings Ultimate HPLC system equipped with a Famos autosampler (Dionex, Leeds, UK) interfaced with a Q-Tof Ultima Global mass spectrometer (Waters Micromass, Manchester, UK). Chromatographic separation was achieved using a $2 \times 250$ $\mathrm{mm}$ microbore NP-HPLC TSK gel Amide- 80 column with the same gradient and solvents as used with the standard NP-HPLC but at a lower flow rate of $40 \mu \mathrm{l} /$ minute. The mass spectrometer was operated in positive ion mode with $3-\mathrm{kV}$ capillary voltage and cone voltage $30 \mathrm{~V}, 60-\mathrm{mm} \mathrm{RF}$ lens, source temperature $100{ }^{\circ} \mathrm{C}$, desolvation temperature $150^{\circ} \mathrm{C}$, cone gas flow $50 \mathrm{l} / \mathrm{h}$, desolvation gas flow $450 \mathrm{l} / \mathrm{h}$, TOF survey scan time $1 \mathrm{~s}$, mass range $m / z$ 50-2300. Spectra were acquired and processed with MassLynx software, version 4.0. The masses in Table 2 and the spectra in Fig. 6 were processed with MaxEnt 3 software incorporated into MassLynx to convert $[\mathrm{M}+2 \mathrm{H}]^{2+}$ ions to their singly charged counterparts.

\section{Results}

rhEPO expressed in goat milk and its hematopoietic activity

rhEPO-milk from goats showed less heterogeneity with a narrower molecular weight range and a slightly higher migration on SDS-PAGE gels than the glycoprotein from CHO-EPO (Fig. 1A and B). The in vivo hematopoietic activity assay showed that the rhEPO-milk had a lower activity than the homologous CHO-EPO. Significantly, doses of $8 \mu \mathrm{g}$ of CHO-EPO exhibited more hematopoietic activity than large doses (10-12 $\mu \mathrm{g})$ of rhEPO-milk (Fig. 1C).

\section{Protein characterization}

No changes in the protein backbone were observed by mass spectrometric analysis of the tryptic digestion products from $N$-deglycosylated rhEPO-milk. The disulfide bonds between Cys 7-161 and 29-33 were confirmed. In addition, this experiment revealed that the three potential $N$-glycosylation sites (Asn 24, 38 and 83) were occupied while Ser 126 ( $O$-glycan) was only partially occupied (Table 1 ).

\section{Glycosylation analysis}

\section{Lectin binding assays and sialic acid content}

Complex type structures were detected in the rhEPOmik using the specific binding lectins digoxigenin-labeled 
A

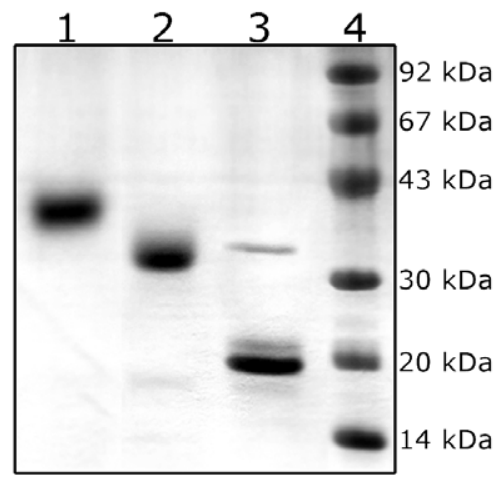

B

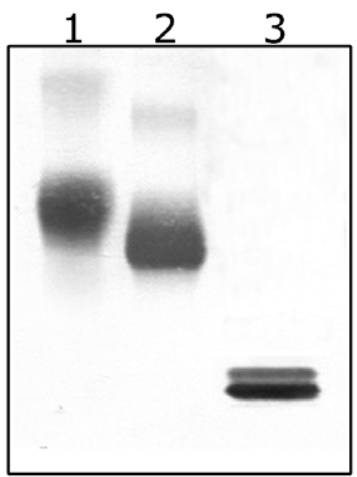

C

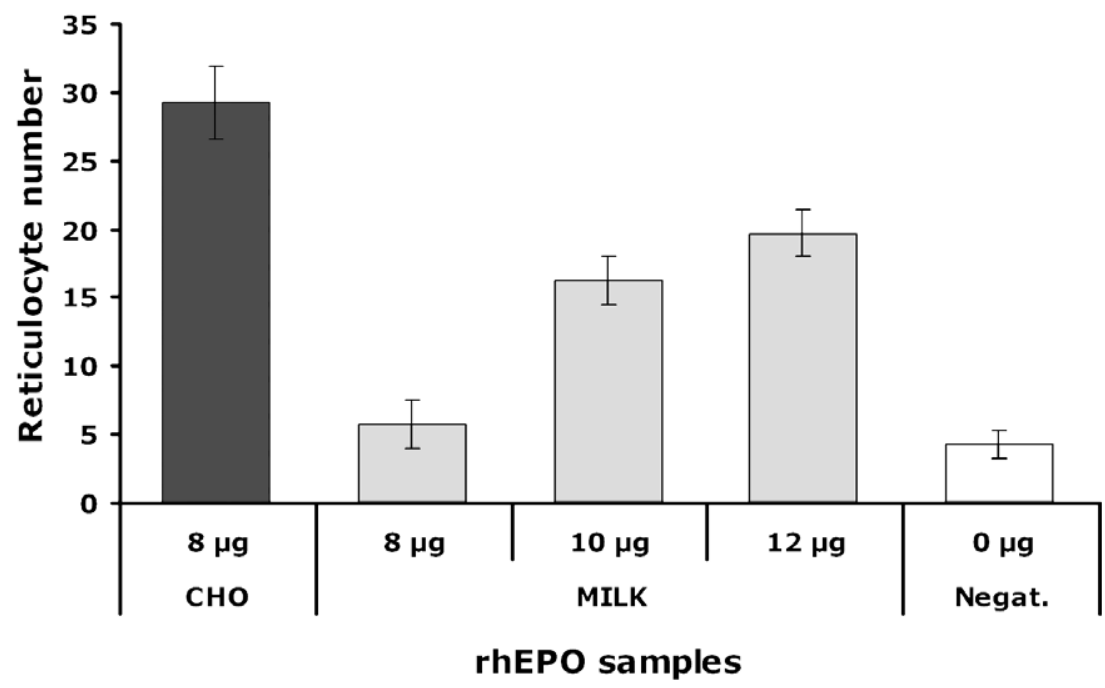

Fig. 1. (A and B) Homogeneity analysis of rhEPO purified from goat milk. Samples 1: CHO-EPO; 2: rhEPO-milk; 3: $N$-deglycosylated rhEPO-milk (A) $12 \%$ SDS-PAGE rhEPO-milk (B) Western-blotting of (A) developed using monoclonal anti-EPO conjugated to HRP. (C) In vivo hematopoietic activity assay of CHO-EPO and rhEPO-milk at a range of doses. Samples were subcutaneously inoculated into B6D2F1 normocytic mice, the reticulocytes were counted after 4 days. The figure shows the mean and SD from three experiments.

assay. The strong signal by incubation with Datura stramoniun lectin (DSA) indicates a large proportion of complextype $N$-glycans. The faint signal by Galanthus nivalis lectin (GNA) suggests that oligomannosides were not present in significant amounts. Differential binding by Sambucus nigra (SNA) and Maackia amurensis (MAA) lectins indicated that sialic acids were mostly $\alpha 2,6$-linked to the oligosaccharide terminal antennae in the rhEPO-milk, in contrast to the reference CHO-EPO where the sialic acid was predominantly $\alpha 2,3$-linked (Fig. 2).

Analysis of sialic acid content by reversed-phase HPLC (as DMB-derivatives) of the $N$-glycans from rhEPO-milk showed the presence of $N$-acetyl- and $N$-glycolylneuraminic acids in a 1:1 ratio, capping the oligosaccharide chains, in contrast to the major presence of Neu5Ac linked to the non-reducing terminal arms in glycans from reference CHO-EPO (Fig. 3).

\section{HPLC N-glycan profiles of rhEPO-milk}

$\mathrm{N}$-Glycans from rhEPO-milk were enzymatically released by PNGase $\mathrm{F}$ and labeled with 4 -aminobenzoic acid. Most of $N$-glycans eluted at low retention times indicating a high proportion of low branching and low sialylat-

Table 1

ESI-MS of the trypic digestion of $N$-deglycosylated rhEPO-milk

\begin{tabular}{llll}
\hline Peptides/(glyco)peptides $^{\mathrm{a}}$ & $\mathrm{m} / \mathrm{z}_{\text {exp. }}$ & $\mathrm{m} / \mathrm{z}_{\text {cal. }}$ & $Z$ \\
\hline${ }^{5}$ LICDSR $^{10155}$ LYTGEACR $^{162}$ & 808.37 & 808.38 & 2 \\
${ }^{15}$ YLLEAK $^{20}$ & 736.41 & 736.41 & 1 \\
$^{21}$ EAEDITTGCAEHCSLNEDITVPDTK $^{45}$ & 897.04 & 896.41 & 3 \\
${ }^{46}$ VNFYAWK $^{52}$ & 464.24 & 464.24 & 2 \\
${ }^{54}$ MEVGQQAVEVWQGLALLSEAVLR $^{76}$ & 842.78 & 842.78 & 3 \\
77 $^{77}$ GQALLVDSSQPWEPLQLHVDK $^{97}$ & 787.40 & 787.08 & 3 \\
${ }^{98}$ AVSGLR $^{103}$ & 602.36 & 602.33 & 1 \\
${ }^{104}$ SLTTLLR $^{110}$ & 803.47 & 803.50 & 1 \\
I17 $^{117}$ EAISPPDAASAAPLR $^{131}$ & 733.38 & 733.39 & 2 \\
${ }^{132}$ TITADTFR $^{139}$ & 462.75 & 462.74 & 2 \\
${ }^{144}$ VYSNFLR $^{150}$ & 449.73 & 449.74 & 2 \\
\hline
\end{tabular}

${ }^{\text {a }}$ Peptide ${ }^{5} \mathrm{~L}-{ }^{10} \mathrm{R}$ to ${ }^{155} \mathrm{~L}-{ }^{162} \mathrm{R}$ confirmed the existence of an inter disulfide bond between Cysteins 7 and 161 , while peptide ${ }^{21} \mathrm{E}-{ }^{45} \mathrm{~K}$ confirmed the disulfide bond between Cysteins 29 and 33. The glycopeptides ${ }^{21} \mathrm{E}-{ }^{45} \mathrm{~K}$ and ${ }^{77} \mathrm{G}-{ }^{97} \mathrm{~K}$ enclosed the three $N$-glycosylation sites in which the $N$ residues were changed to $\mathrm{D}$ following the enzymatic deglycosylation. The peptide ${ }^{117} \mathrm{E}-{ }^{131} \mathrm{R}$ was found at the expected $\mathrm{m} / \mathrm{z}$ value suggesting a very low $O$-glycosylation event. 
ed structures probably of the biantennary type $N$-glycans (Fig. 4A). Anion exchange separation gave two fractions of which the charged one is more abundant (Fig. 4B). Each fraction was further resolved by NP-HPLC (Fig. 4C) giving similar patterns suggesting similar populations of neutral and sialyated $N$-glycans.

\section{Mass Spectrometric characterization of rhEPO-milk $N$-glycans}

The 4ABA-derived $N$-glycans neutral and charged fractions from anion exchange HPLC were analyzed by mass spectrometry. MALDI-MS, ESI-MS (direct infusion) and LC-ESI-MS gave constituent monosaccharide compositions as listed in Table 2.

The MALDI-TOF MS spectrum in the positive mode of the neutral fraction (Fig. 5A) gave the $[\mathrm{M}+\mathrm{Na}]^{+}$ions. The three most abundant ions with $\mathrm{m} / \mathrm{z}$ 2012.7, 1971.7 and 1930.6 were assigned to the monosaccharide composition $\mathrm{Hex}_{3} \mathrm{HexNAc}_{6} \mathrm{dHex}, \mathrm{Hex}_{4} \mathrm{HexNAc}_{5} \mathrm{dHex}$ and $\mathrm{Hex}_{5} \mathrm{HexNAc} \mathrm{dH}_{4} \mathrm{Hex}$, respectively. The HexNAc con-
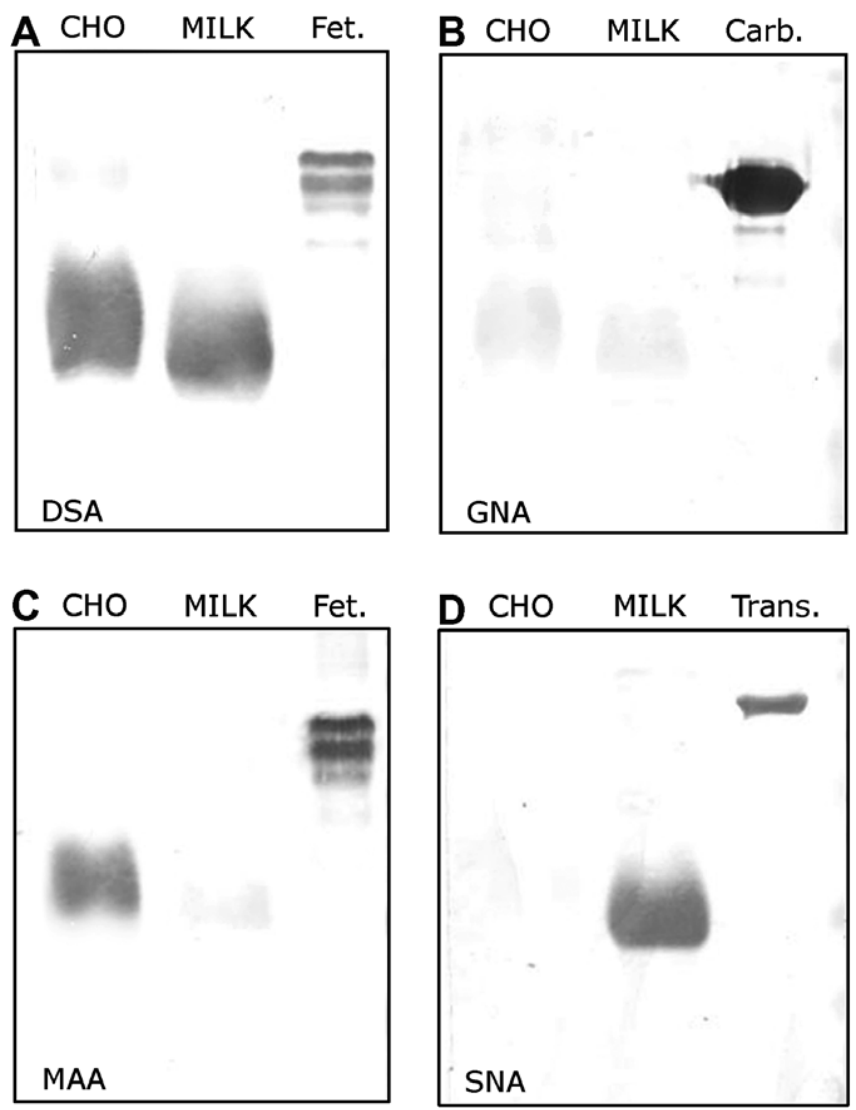

Fig. 2. Results of Lectin binding assays. The "DIG Glycans Differentiation Kit" was used to identify specific carbohydrate motives. (A) Datura stramonium lectin (DSA): recognizes Gal( $(\beta 1,4)-G l c N A c$ in complex and hybrid $N$-glycans; (B) GNA: recognizes terminal mannose, $\alpha 1,3-, \alpha 1,6-$ or $\alpha 1,2$-linked; (C) MAA: recognizes $\alpha 2,3$-linked sialic acid and (D) SNA: recognizes $\alpha 2,6$-linked sialic acid. CHO: CHO-EPO; Milk: rhEPO-milk. Fetuin (Fet), Carboxypeptidase Y (Carb) and Transferrin (Trans) were used as positive controls. tent of these $N$-glycans suggested variable numbers of lactosediamine (GalNAc-GlcNAc) antennae in addition to the classical Gal-GlcNAc present in CHO-EPO. The charged fraction was analyzed by negative ion ESI-MS resulting in the $[\mathrm{M}-2 \mathrm{H}]^{2-}$ ions (see Fig. 5B). The compounds found were similar to those identified in the neutral fraction but were mostly monosialylated with Neu5Ac or Neu5Gc. Evidence of disialylation was observed for $N$-glycans with compositions $\mathrm{Hex}_{3} \mathrm{HexNAc}_{6}\left(\mathrm{NeuAc}_{2} \quad(\mathrm{~m} / \mathrm{z}\right.$ 1211.7), and $\mathrm{Hex}_{3} \mathrm{HexNAc}_{6} \mathrm{dHex}(\mathrm{NeuAc})_{2}(\mathrm{~m} / \mathrm{z}$ 1284.7).

The same fractions were also analyzed by LC-MS (see Table 2). Fig. 6A and B show the combined spectra of the DEAE neutral and charged fractions, respectively. Disialylated $N$-glycans were not found by LC-MS probably due to stronger retention in the LC column.

\section{Collision induced fragmentation spectra of the most abundant species}

\section{Neutral N-glycans}

The ESI-MS/MS spectrum (see [24]) of the most abundant neutral 4ABA-labeled $N$-glycan $\left([\mathrm{M}-\mathrm{H}]^{-}\right.$ion at $\mathrm{m} / \mathrm{z}$

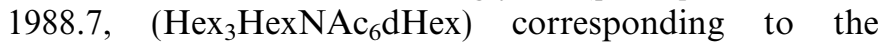
MALDI and LC-MS ions at $m / z 2012.7\left([\mathrm{M}+\mathrm{Na}]^{+}\right)$and $1991.0\left([\mathrm{M}-\mathrm{H}]^{-}\right)$, respectively, is shown in Fig. 7A. The nomenclature used for describing the fragment ions is that proposed by Domon and Costello [25]. The base ion at $\mathrm{m} / \mathrm{z}$ 465 , corresponded to $\mathrm{HexNAc}_{2}+59$ mass units $\left({ }^{1,3} \mathrm{~A}_{3}\right)$. Other fragment ions at $m / z 262\left(\mathrm{HexNAc}+59,{ }^{1,3} \mathrm{~A}_{2}\right)$ and $m / z 202\left(\mathrm{~B}_{1}\right)$ were characteristic of HexNAc at non-reducing terminals. The absence of signals at $m / z 179$ (Hex) and 365 (Hex-HexNAc) confirm that there are no antennae ending with Gal-GlcNAc in this compound. Additionally, an ion at $m / z 469$ can be attributed to the $Z_{1}$ ion (Fuc-GlcNAc-4ABA), from the oligosaccharide-reducing end. Hence, the $N$-glycan can be deduced to be a core-fucosylated biantennary glycan with two $N, N^{\prime}$-diacetyllactosediamine antennae. The compound with composition $\mathrm{Hex}_{5} \mathrm{HexNAc}_{4}$ dHex (MALDI-MS $[\mathrm{M}+\mathrm{Na}]^{+} \mathrm{m} / \mathrm{z}-1930.6$ and LC-MS $[\mathrm{M}+\mathrm{H}]^{+} \mathrm{m} / z$-1909.0) showed fragment ions at $m / z 424\left({ }^{1,3} \mathrm{~A}_{3}\right)$ and $179\left(\mathrm{C}_{1}\right)$ consistent with a biantennary structure bearing two Gal-GlcNAc arms (spectrum not shown).

\section{Charged $\mathrm{N}$-glycans}

$\mathrm{MS} / \mathrm{MS}$ analysis from the ion at $m / z 1147.5[\mathrm{M}-2 \mathrm{H}]^{2-}$ $\mathrm{Hex}_{3} \mathrm{HexNAc}_{6} \mathrm{dHexNeuGc}$ from ESI-MS and LC-MS $[\mathrm{M}+\mathrm{H}]^{+} \mathrm{m} / \mathrm{z} 2298.1$ gave fragment ions at $\mathrm{m} / \mathrm{z} 202$ and 306, which were assigned to HexNAc (GlcNAc or GalNAc) and Neu5Gc, respectively. The ion at $m / z 465$ was indicative of the structure HexNAc-HexNAc +59 , $\left({ }^{1,3} \mathrm{~A}_{n}\right)$ for the non-reducing terminal, typical of a GalNAc-GlcNAc antenna, confirming the presence of the lactosediamine motif. Moreover, no ion at $\mathrm{m} / \mathrm{z} 424$ suggested the absence of Gal-GlcNAc-containing arms in this $N$-glycan. The strong ion signal at $\mathrm{m} / \mathrm{z} 712$ could be assigned to a single Neu5Gc residue capping one GalNAc-GlcNAc 


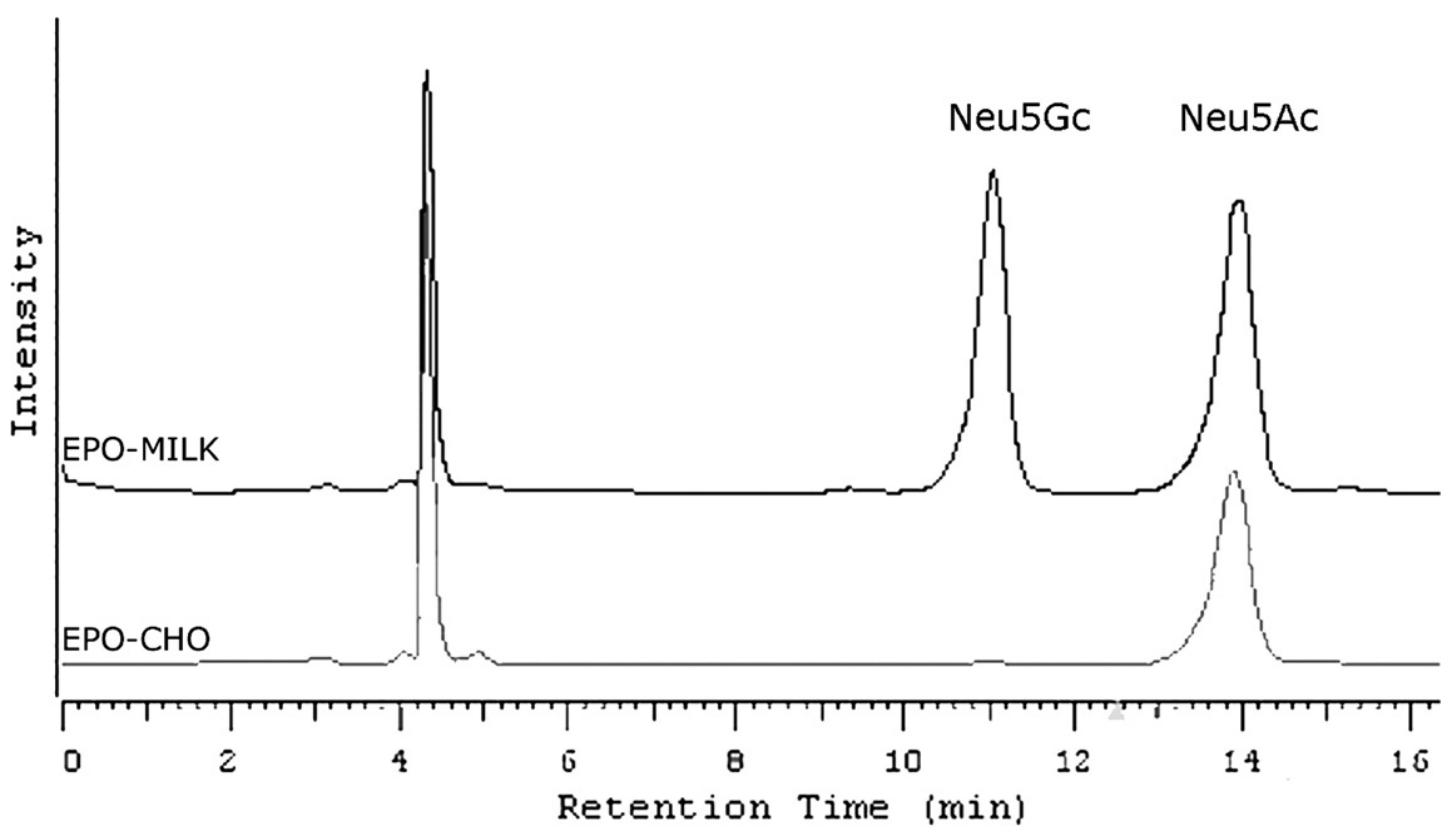

Fig. 3. Sialic acid analysis of DMB-labeled sialic acids. CHO-EPO showed almost solely Neu5Ac whereas equal amounts of Neu5Ac and Neu5Gc were detected in rhEPO-Milk.

A

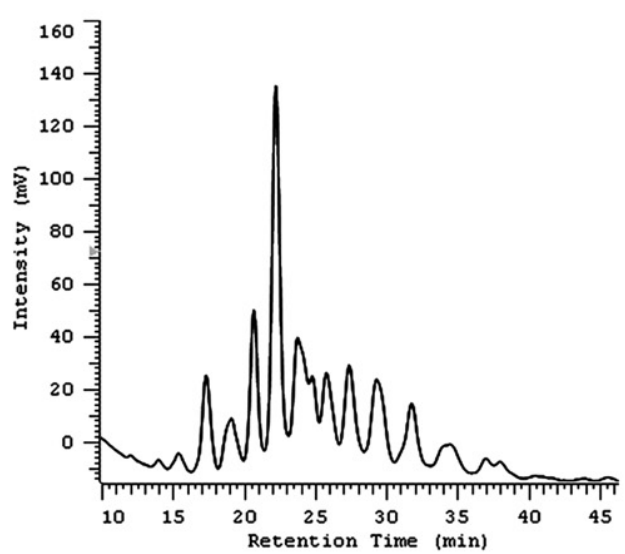

C

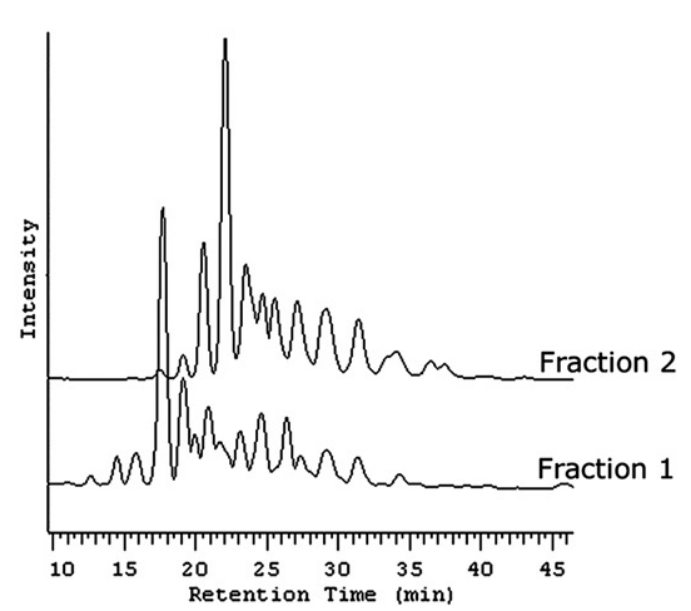

Fig. 4. 4ABA labeled $N$-glycan separation by normal phase and anion exchange HPLC. (A) rhEPO-milk $N$-glycans separation by NP-HPLC. (B) rhEPOmilk $N$-glycans separated by anion exchange chromatography (DEAE-HPLC). (C) NP-HPLC Amide-80 profiles of fractions 1 and 2 from the DEAE separation.

\section{B}

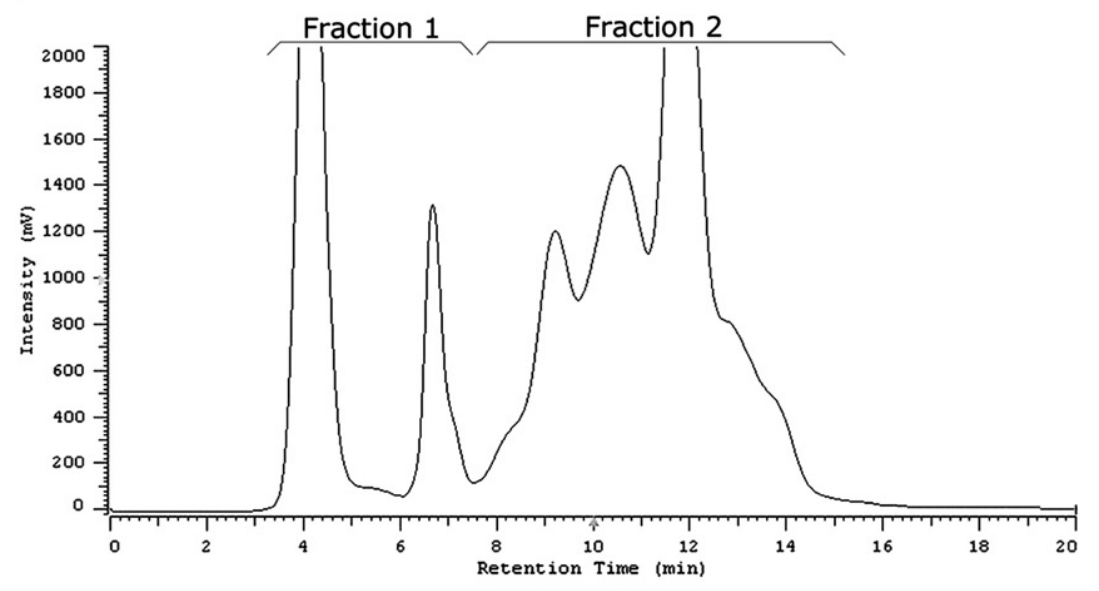


Table 2

Relative monosaccharide composition of 4ABA labeled $N$-glycans from rhEPO-milk calculated by mass spectrometry analysis (MALDI-MS $[\mathrm{M}+\mathrm{Na}]^{+}$, ESI-MS $[\mathrm{M}-2 \mathrm{H}]^{2-}$ and LC-MS $[\mathrm{M}+\mathrm{H}]^{+}$

\begin{tabular}{|c|c|c|c|c|c|c|c|c|c|c|c|c|}
\hline \multicolumn{2}{|c|}{$\begin{array}{l}\text { MALDI-MS fraction } 1 \\
\mathrm{~m} / \mathrm{z}[\mathrm{M}+\mathrm{Na}]^{+}\end{array}$} & \multicolumn{2}{|c|}{$\begin{array}{l}\text { ESI-MS fraction } 2 \\
m / z[\mathrm{M}-2 \mathrm{H}]^{2-}\end{array}$} & \multicolumn{5}{|c|}{ Monosaccharide composition } & \multicolumn{2}{|c|}{$\begin{array}{l}\text { LC-MS fraction } 1 \\
m / z[\mathrm{M}+\mathrm{H}]^{+}\end{array}$} & \multicolumn{2}{|c|}{$\begin{array}{l}\text { LC-MS fraction } 2 \\
m / z[\mathrm{M}+\mathrm{H}]^{+}\end{array}$} \\
\hline Found & Calc. & Found & Calc. & Hex & HexNAc & dHex & Neu5Ac & Neu5Gc & Found & Calc. & Found & Calc. \\
\hline \multirow[t]{3}{*}{1606.7} & 1606.1 & & & 3 & 4 & 1 & & & 1584.6 & 1584.6 & & \\
\hline & & - & 936.4 & 3 & 4 & 1 & 1 & 0 & & & - & 1875.7 \\
\hline & & - & 944.4 & 3 & 4 & 1 & 0 & 1 & & & 1891.7 & 1891.7 \\
\hline \multirow[t]{3}{*}{1809.7} & 1809.7 & & & 3 & 5 & 1 & & & 1787.7 & 1787.7 & & \\
\hline & & - & 1037.9 & 3 & 5 & 1 & 1 & 0 & & & - & 2078.8 \\
\hline & & - & 1045.9 & 3 & 5 & 1 & 0 & 1 & & & - & 2094.7 \\
\hline \multirow[t]{3}{*}{2012.7} & 2012.7 & & & 3 & 6 & 1 & & & 1990.7 & 1990.7 & & \\
\hline & & 1139.5 & 1139.4 & 3 & 6 & 1 & 1 & 0 & & & 2281.9 & 2281.8 \\
\hline & & 1147.4 & 1147.4 & 3 & 6 & 1 & 0 & 1 & & & 2297.8 & 2297.8 \\
\hline \multirow[t]{3}{*}{2158.3} & 2158.1 & & & 3 & 6 & 2 & & & 2136.8 & 2136.8 & & \\
\hline & & - & 1212.4 & 3 & 6 & 2 & 1 & 0 & & & - & 2427.9 \\
\hline & & - & 1220.4 & 3 & 6 & 2 & 0 & 1 & & & 2443.9 & 2443.9 \\
\hline \multirow[t]{3}{*}{2418.8} & 2418.9 & & & 3 & 8 & 1 & & & 2397.0 & 2396.9 & & \\
\hline & & 1342.5 & 1342.5 & 3 & 8 & 1 & 1 & 0 & & & 2688.0 & 2688.0 \\
\hline & & 1350.5 & 1350.5 & 3 & 8 & 1 & 0 & 1 & & & 2704.0 & 2704.0 \\
\hline \multirow[t]{3}{*}{1565.6} & 1565.6 & & & 4 & 3 & 1 & & & - & 1543.6 & & \\
\hline & & - & 915.8 & 4 & 3 & 1 & 1 & 0 & & & - & 1834.7 \\
\hline & & - & 923.8 & 4 & 3 & 1 & 0 & 1 & & & - & 1850.7 \\
\hline \multirow[t]{3}{*}{1768.7} & 1768.6 & & & 4 & 4 & 1 & & & 1746.6 & 1746.7 & & \\
\hline & & - & 1017.4 & 4 & 4 & 1 & 1 & 0 & & & 2037.7 & 2037.7 \\
\hline & & - & 1025.4 & 4 & 4 & 1 & 0 & 1 & & & 2053.7 & 2053.7 \\
\hline 1971.7 & 1971.7 & & & 4 & 5 & 1 & & & 1949.7 & 1949.7 & & \\
\hline & & 1118.9 & 1118.9 & 4 & 5 & 1 & 1 & 0 & & & 2240.8 & 2240.8 \\
\hline & & 1126.9 & 1126.9 & 4 & 5 & 1 & 0 & 1 & & & 2256.8 & 2256.8 \\
\hline 2028.6 & 2028.7 & & & 4 & 6 & 0 & & & - & 2006.7 & & \\
\hline & & 1147.4 & 1147.4 & 4 & 6 & 0 & 1 & 0 & & & - & 2297.8 \\
\hline & & 1155.0 & 1155.4 & 4 & 6 & 0 & 0 & 1 & & & - & 2313.8 \\
\hline 2377.8 & 2377.9 & & & 4 & 7 & 1 & & & 2355.9 & 2355.9 & & \\
\hline & & 1322.0 & 1322.0 & 4 & 7 & 1 & 1 & 0 & & & 2647.0 & 2647.0 \\
\hline & & 1330.0 & 1330.0 & 4 & 7 & 1 & 0 & 1 & & & 2663.0 & 2663.0 \\
\hline 1784.6 & 1784.6 & & & 5 & 4 & 0 & & & - & 1762.6 & & \\
\hline & & - & 1025.4 & 5 & 4 & 0 & 1 & 0 & & & 2053.8 & 2053.7 \\
\hline & & - & 1033.4 & 5 & 4 & 0 & 0 & 1 & & & 2069.8 & 2069.7 \\
\hline 1930.6 & 1930.7 & & & 5 & 4 & 1 & & & 1908.7 & 1908.7 & & \\
\hline & & 1098.4 & 1098.4 & 5 & 4 & 1 & 1 & 0 & & & 2199.8 & 2199.8 \\
\hline & & 1106.4 & 1106.4 & 5 & 4 & 1 & 0 & 1 & & & 2215.8 & 2215.8 \\
\hline 2133.8 & 2133.8 & & & 5 & 5 & 1 & & & 2111.8 & 2111.8 & & \\
\hline & & 1200.0 & 1199.9 & 5 & 5 & 1 & 1 & 0 & & & 2402.9 & 2402.9 \\
\hline & & - & 1207.9 & 5 & 5 & 1 & 0 & 1 & & & - & 2418.9 \\
\hline 2336.8 & 2336.8 & & & 5 & 6 & 1 & & & 2314.9 & 2314.9 & & \\
\hline & & 1301.5 & 1301.5 & 5 & 6 & 1 & 1 & 0 & & & 2605.9 & 2606.0 \\
\hline & & 1309.5 & 1309.5 & 5 & 6 & 1 & 0 & 1 & & & 2621.9 & 2622.0 \\
\hline 2742.8 & 2743.0 & & & 5 & 8 & 1 & & & 2721.0 & 2721.0 & & \\
\hline & & - & 1504.5 & 5 & 8 & 1 & 1 & 0 & & & - & 3012.1 \\
\hline & & 1512.6 & 1512.5 & 5 & 8 & 1 & 0 & 1 & & & - & 3028.1 \\
\hline 1889.6 & 1889.7 & & & 6 & 3 & 1 & & & - & 1867.7 & & \\
\hline & & 1077.6 & 1077.8 & 6 & 3 & 1 & 1 & 0 & & & - & 2158.8 \\
\hline & & - & 1085.8 & 6 & 3 & 1 & 0 & 1 & & & 2174.8 & 2174.8 \\
\hline 2093.0 & 2092.7 & & & 6 & 4 & 1 & & & 2070.0 & 2070.0 & & \\
\hline & & 1179.4 & 1179.4 & 6 & 4 & 1 & 1 & 0 & & & - & 2361.8 \\
\hline & & - & 1187.4 & 6 & 4 & 1 & 0 & 1 & & & - & 2377.8 \\
\hline 2295.7 & 2295.8 & & & 6 & 5 & 1 & & & 2273.8 & 2273.8 & & \\
\hline & & 1281.0 & 1281.0 & 6 & 5 & 1 & 1 & 0 & & & 2565.0 & 2564.9 \\
\hline & & 1289.0 & 1289.0 & 6 & 5 & 1 & 0 & 1 & & & 2580.9 & 2580.9 \\
\hline 2701.8 & 2702.0 & & & 6 & 7 & 1 & & & 2679.9 & 2680.0 & & \\
\hline & & 1484.0 & 1484.0 & 6 & 7 & 1 & 1 & 0 & & & - & 2971.1 \\
\hline & & 1492.1 & 1492.0 & 6 & 7 & 1 & 0 & 1 & & & 2987.1 & 2987.1 \\
\hline 2660.9 & 2661.0 & & & 7 & 6 & 1 & & & 2638.9 & 2639.0 & & \\
\hline & & 1463.5 & 1463.5 & 7 & 6 & 1 & 1 & 0 & & & 2930.0 & 2930.1 \\
\hline & & 1471.5 & 1471.5 & 7 & 6 & 1 & 0 & 1 & & & 2946.0 & 2946.1 \\
\hline
\end{tabular}


Table 2 (continued)

\begin{tabular}{|c|c|c|c|c|c|c|c|c|c|c|c|c|}
\hline \multicolumn{2}{|c|}{$\begin{array}{l}\text { MALDI-MS fraction } 1 \\
m / z[\mathrm{M}+\mathrm{Na}]^{+}\end{array}$} & \multicolumn{2}{|c|}{$\begin{array}{l}\text { ESI-MS fraction } 2 \\
m / z[\mathrm{M}-2 \mathrm{H}]^{2-}\end{array}$} & \multicolumn{5}{|c|}{ Monosaccharide composition } & \multicolumn{2}{|c|}{$\begin{array}{l}\text { LC-MS fraction } 1 \\
m / z[\mathrm{M}+\mathrm{H}]^{+}\end{array}$} & \multicolumn{2}{|c|}{$\begin{array}{l}\text { LC-MS fraction } 2 \\
m / z[\mathrm{M}+\mathrm{H}]^{+}\end{array}$} \\
\hline Found & Calc. & Found & Calc. & Hex & HexNAc & dHex & Neu5Ac & Neu5Gc & Found & Calc. & Found & Calc. \\
\hline \multirow[t]{3}{*}{2619.8} & 2619.9 & & & 8 & 5 & 1 & & & 2598.0 & 2597.9 & & \\
\hline & & 1443.0 & 1443.0 & 8 & 5 & 1 & 1 & 0 & & & 2889.1 & 2889.0 \\
\hline & & - & 1451.0 & 8 & 5 & 1 & 0 & 1 & & & - & 2905.0 \\
\hline
\end{tabular}
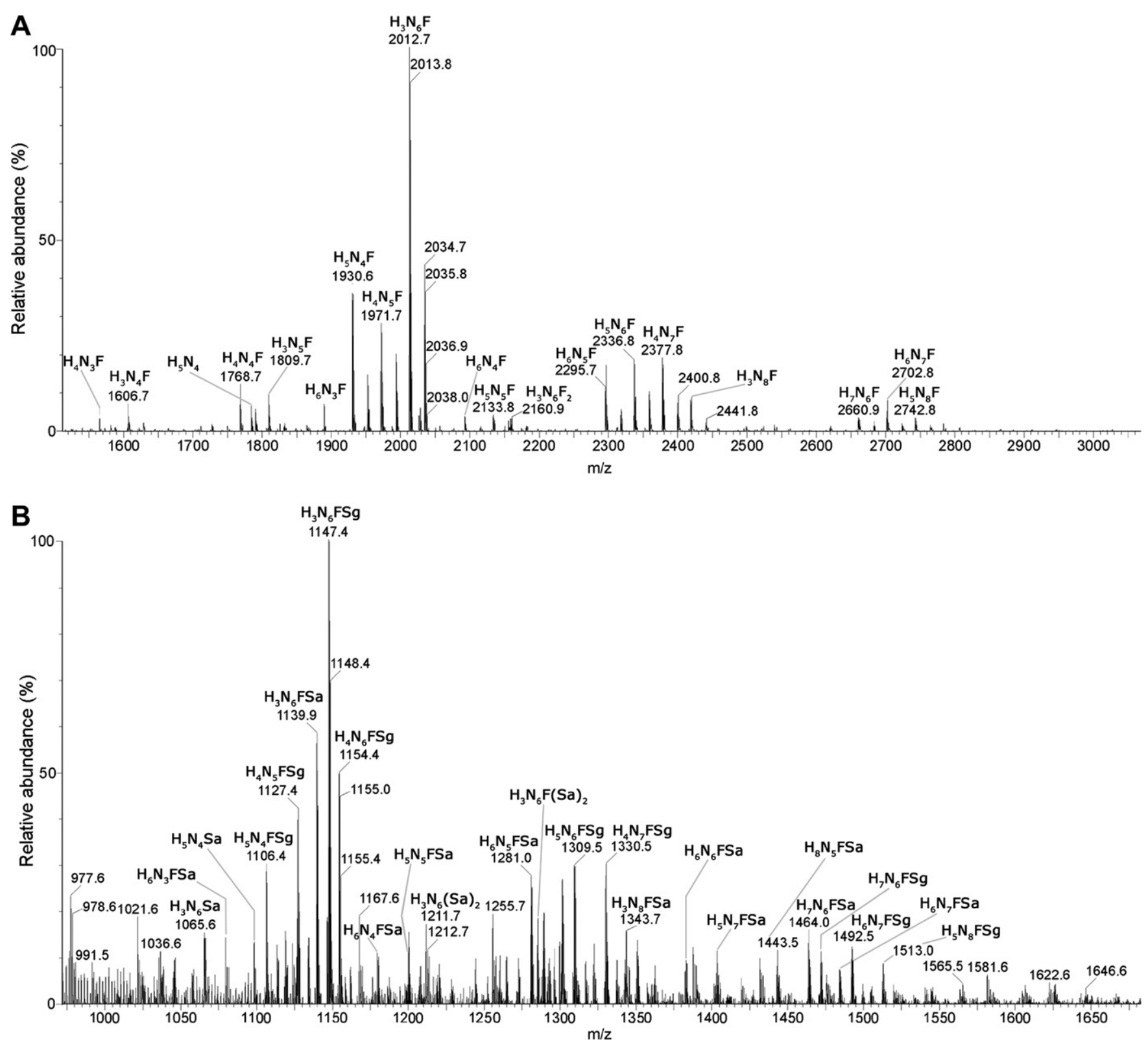

Fig. 5. Mass spectra of DEAE fractions 1 and 2 from goat milk $N$-glycans. (A) MALDI-TOF-MS, positive mode, [M+Na $]^{+}$ions, neutral fraction. (B) ESI-MS, negative mode, $[\mathrm{M}-2 \mathrm{H}]^{2-}$ ions of the charged fraction. $N$-Glycan structural assignments based on the monosaccharide composition from the experimental $\mathrm{m} / \mathrm{z}$ values are represented by a single letter code as follows: Hexose:H; HexNAc:N; dHex:F; NeuAc:Sa and NeuGc:Sg.

antenna. The [D-18] ion from the upper antenna without Neu5Gc would give also a signal at 712, suggesting sialylation probably occurring at the lower arm. Thus, $\mathrm{Hex}_{3} \mathrm{Hex}$ $\mathrm{NAc}_{6} \mathrm{dHexNeuGc}_{\mathrm{H}}$ a monosialylated ( $N$-Glycolyl) core- fucosylated biantennary structure having GalNAc-Glc NAc branches on each antenna (Fig. 7B). Similar fragmentation pattern was observed for $\mathrm{Hex}_{3} \mathrm{HexNAc}_{6} \mathrm{dHexNeuAc}$ (ESI-MS [M-2H] $\left.]^{2-} m / z 1139.5\right)$ but 16 mass units less for 

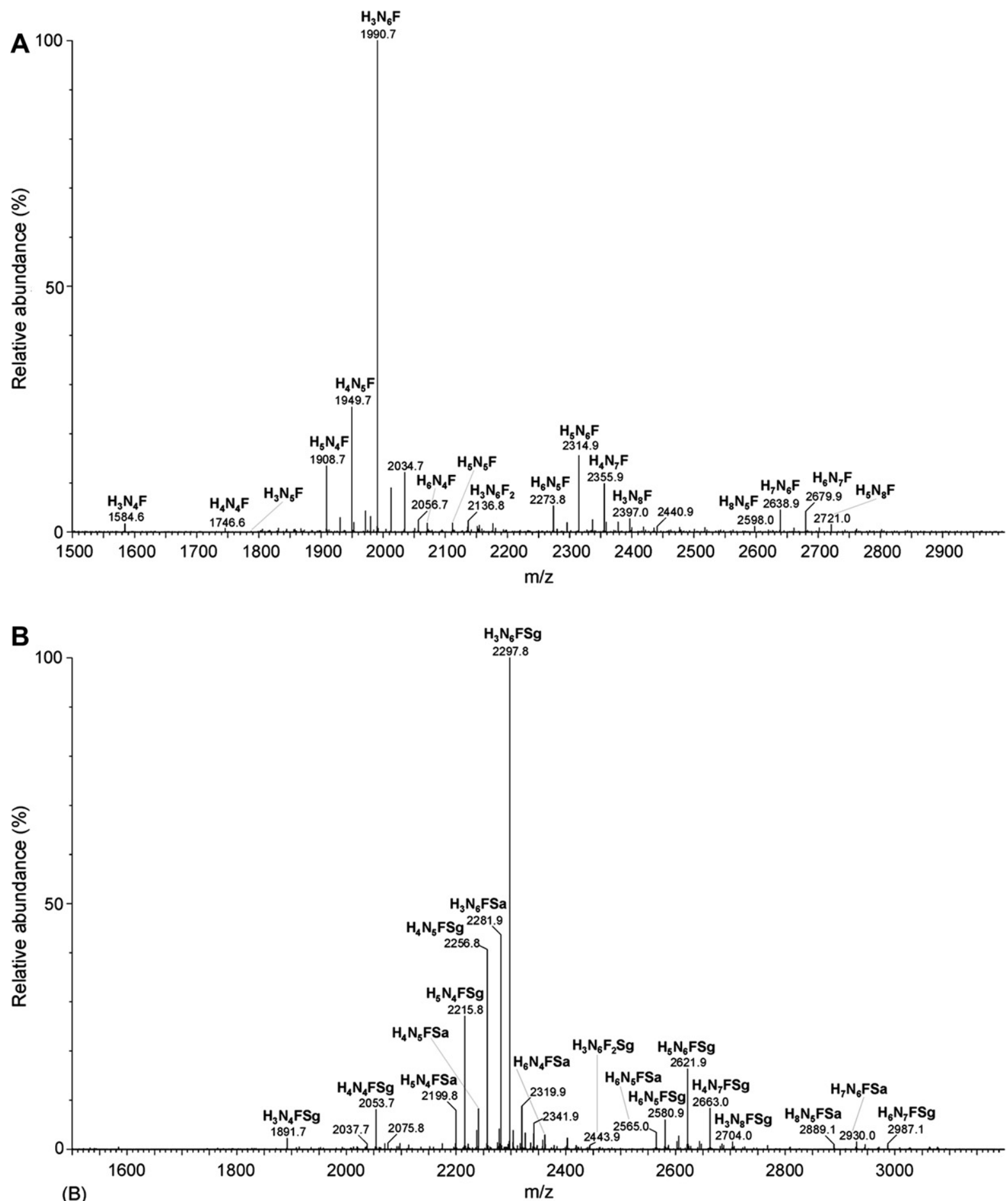

Fig. 6. LC-MS of DEAE fractions 1 and 2 from goat milk $N$-glycans. (A) Combined electrospray spectrum of the $N$-glycans from DEAE fraction 1 . (B) Combined electrospray spectrum of the $N$-glycans from DEAE fraction 2. The spectra were recorded in the positive mode as $[\mathrm{M}+\mathrm{H}]^{+}$ions. $N$-Glycan structural assignments based on the experimental $\mathrm{m} / \mathrm{z}$ values are represented by the single letter code described in Fig. 5 .

those ions bearing sialic acid, i.e., 290 and 696 instead of 306 and 712, respectively (spectrum not shown).

MS/MS results confirmed that the most abundant oligosaccharides from the charged fraction were core-fucosylated biantennary structures with atypical GalNAc-GlcNAc disaccharide in each antenna, singly capped with one Neu5Ac or Neu5Gc residue. Although no evidence of a1,3-Gal-Gal terminating antennae was observed in the
MS/MS spectra of the major species, composition data from some low abundance compounds having high hexose content was suggestive of the presence of this motive. In addition $\alpha$-galactosidase digestion of the neutral 4ABAlabeled $N$-glycans showed some minor peaks shifting to lower retention times indicating the presence of $\alpha 1,3-\mathrm{Gal}-$ Gal motives (results not shown). A schematic representation of the most abundant $\mathrm{N}$-glycans is shown in Fig. 8. 


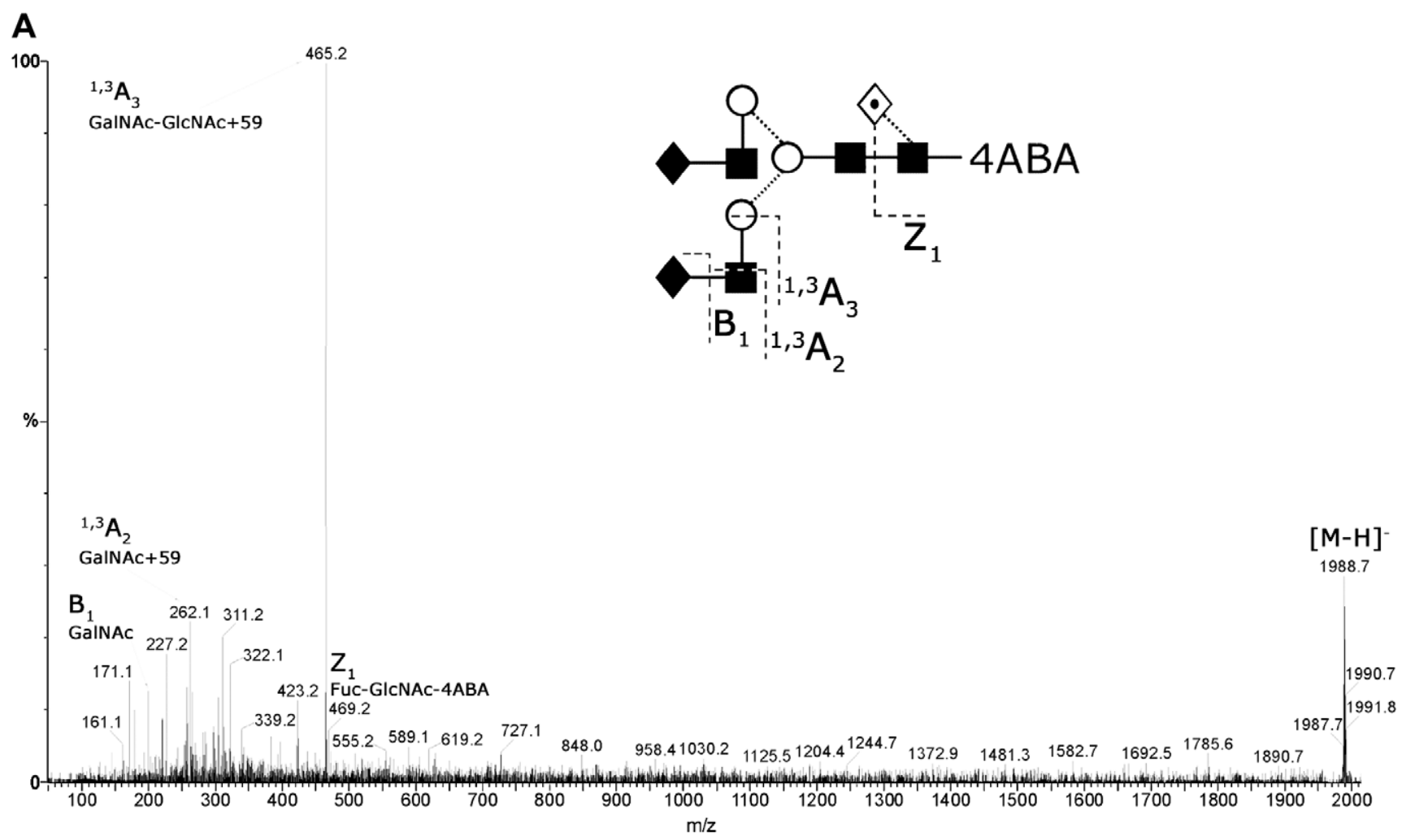

B

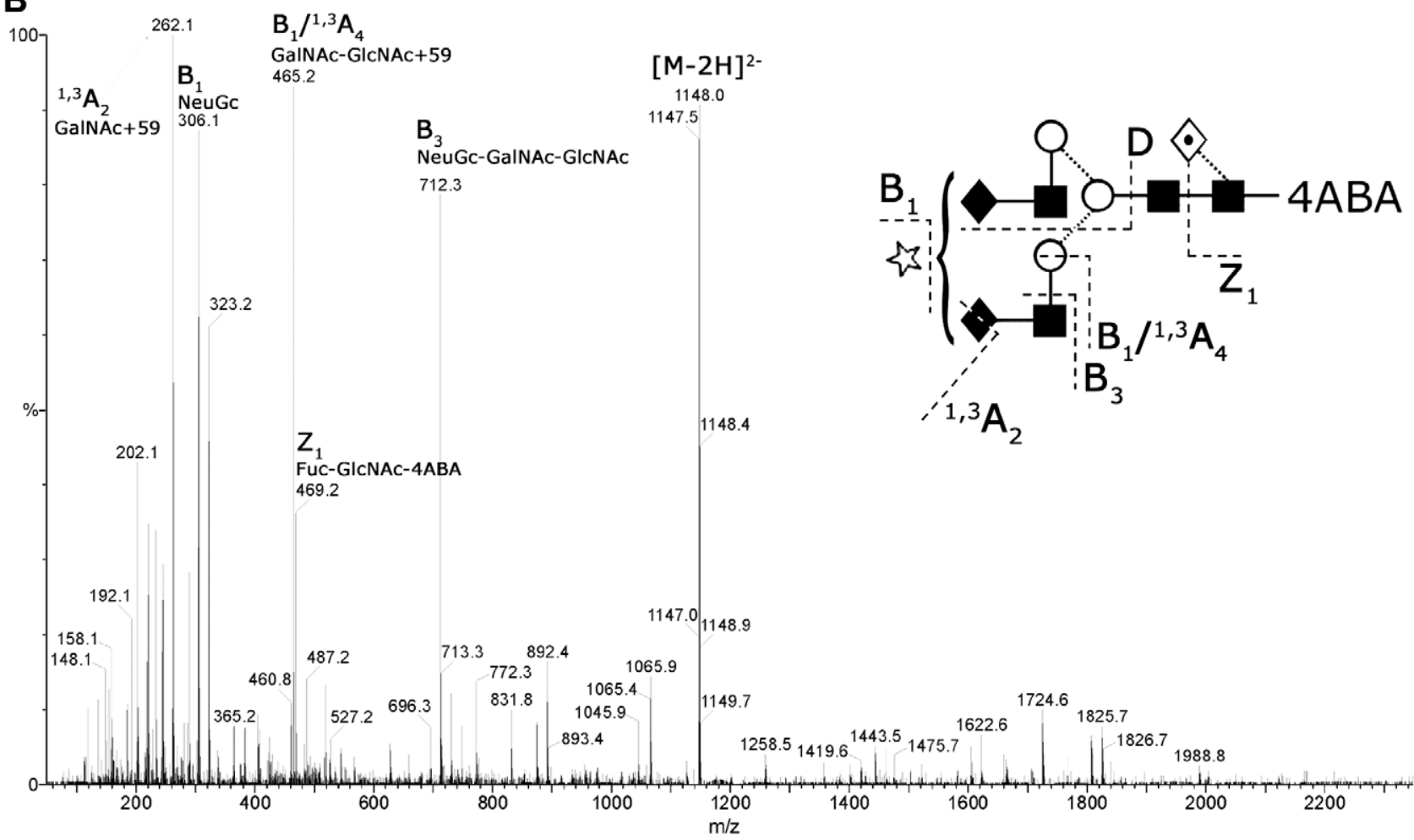

Fig. 7. CID-MS spectra of the most abundant $N$-glycans from the neutral (A) and charged (B) fractions, respectively. The nomenclature used to describe the fragment ions is that proposed by Domon and Costello [25]. Ions retaining the charge on the non-reducing terminus are named A (cross-ring), B, and C (glycosidic), whereas ions retaining the charge on the reducing terminus are $\mathrm{X}$ (cross-ring), $\mathrm{Y}$ and $\mathrm{Z}$, as outlined. (A) ESI-MS/MS of compound $\mathrm{Hex}_{3} \mathrm{HexNAc}_{6} \mathrm{dHex}$. (B) ESI-MS/MS of compound $\mathrm{Hex}_{3} \mathrm{HexNAc}_{6} \mathrm{dHexNeuGc}$ The symbols for the glycan structures are as follows: GlcNAc, black square; GalNAc, black diamond; Man, white circle; Gal, white diamond; Fuc, diamond with a dot inside; Neu5Ac, black star; Neu5Gc, open star. The angle of the lines linking the monosaccharide symbols denotes the linkage positions thus: -, 1,4-linkage; /, 1,3-linkage; \, 1,6-linkage; |, 1,2-linkage. Dotted line, $\alpha$-linkage; solid line, $\beta$-linkage. 


\section{Discussion}

The polypeptide backbone of active $\operatorname{EPO}\left(M_{\mathrm{W}} 34 \mathrm{kDa}\right)$ is built up from 165 amino acids with an average carbohydrate content of about $40 \%$. The three $N$-glycosylation sites (Asn24, Asn-38 and Asn-83) and one $O$-glycosylation site at Ser-126 are generally occupied. The $N$-glycans but not the $O$-glycans are essential for EPO hematopoietic activity. $N$ Glycosylation of urinary EPO [26-28], as well as the recombinant protein expressed in $\mathrm{CHO}$ [27-32] and baby hamster kidney (BHK) cells $[33,34]$ has been fully characterized. The $\mathrm{CHO}$ recombinant form showed complex mixtures of sialylated bi-, tri-, tri' - and tetraantennary core-fucosylated complex $N$-glycans with mainly Gal-GlcNAc chains, $\alpha 2,3$-linked Neu5Ac and minor amount Neu5Gc [29]. $N, N^{\prime}$-Lactosediamine or hybrid-type chains have only been observed before in a BHK cell preparation [33].

rhEPO was expressed at levels of about $2 \mathrm{~g} / \mathrm{L}$ in the milk of goats that had undergone adenoviral transduction of the mammary epithelial cells. The goat mammary gland was able to synthesize and reproduce most of the EPO posttranslational modifications, including disulfide bond formation. However, the milk-derived recombinant hormone showed a lower molecular weight and $N$-glycan HPLC profile that indicated remarkable differences when compared to those already reported CHO-EPO [15] and GMGEEPO [21] using the same fluorophore and separation conditions. In vivo biological (hematopoietic) activity of rhEPO-milk from goats displayed very low activity, even at doses higher than those normally used in this assay. This result suggested that even though the mammary gland cor- rectly synthesizes the recombinant protein; do not reproduce the native glycosylation pattern.

The $N$-glycosylation analysis of rhEPO-milk showed that, although asialo biantennary $N$-glycans terminating with Gal-GlcNAc antennae were present, antennae containing the unusual GalNAc-GlcNAc moieties predominated. Also, the charged $N$-glycans were mainly $\alpha 2,6-$ monosialylated with Neu5Ac or Neu5Gc present in a ratio of 1:1 corresponding to a significant increase in terminal Neu5Gc. Only a low amount of disialylated species $\left(\mathrm{Hex}_{3} \mathrm{HexNAc}_{6}(\mathrm{NeuAc})_{2}\right.$ and $\left.\mathrm{Hex}_{3} \mathrm{HexNAc}_{6} \mathrm{dHex}(\mathrm{NeuAc})_{2}\right)$ were detected. Mostly, $\mathrm{N}$-glycans were core-fucosylated, without evidence of outer-arm fucosylation. Additionally, the presence of glycans with $\alpha 1,3-$ Gal-Gal linkages was detected but in very low proportion. High-mannose glycans, if present at all, were also in very low abundance. The $N$-glycan population from rhEPO expressed in goat milk was less heterogeneous than rhEPO expressed in the mammary goat epithelial cell line GMGE cultured in vitro, even when using the same adenoviral transduction protocol [21].

The relatively high abundance of glycans carrying the GalNAc-GlcNAc epitope is consistent with the glycosylation of glycoproteins found in the milk of other species. Native bovine milk glycoproteins, such as CD36, contain, in addition to high-mannose and hybrid-type glycans, bi-, tri- and tetraantennary complex-type $N$-glycans some of which contain the GalNAc-GlcNAc non-reducing terminal antennae instead of the classical Gal-GlcNAc groups. Some of these GalNAc-GlcNAc groups were capped with $\alpha 2,6$-linked Neu5Ac [35]. Similarly, $N$-glycans from bovine $\alpha$-lactoalbumin comprises a family of neutral

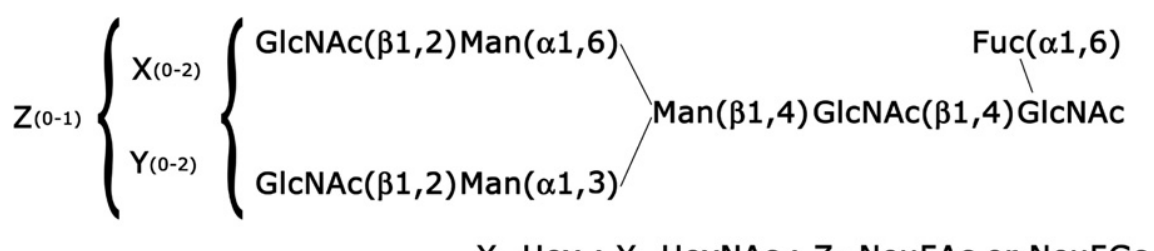

$X=H e x ; Y=H e x N A c ; Z=N e u 5 A c$ or Neu5Gc

\begin{tabular}{c|ccccc} 
& Hex & HexNAc & dHex & Neu5Ac & Neu5Gc \\
\hline Neutral & 3 & 6 & 1 & - & - \\
& 4 & 5 & 1 & - & - \\
& 5 & 4 & 1 & - & - \\
\hline Charged & 3 & 6 & 1 & 1 & - \\
& 3 & 6 & 1 & - & 1 \\
& 4 & 5 & 1 & 1 & - \\
& 4 & 5 & 1 & - & 1 \\
& 5 & 4 & 1 & 1 & - \\
& 5 & 4 & 1 & - & 1
\end{tabular}

Fig. 8. A schematic representation of the most abundant neutral and charged $N$-glycans from rhEPO-milk. Above, a multi-structure proposition of the highly represented biantennary $\mathrm{N}$-glycans. Below, the relative composition in terms of Hex, HexNAc, dHex, Neu5Ac and Neu5Gc. 
and sialylated oligosaccharides with and without fucose having, in a number of cases, GalNAc instead of Gal. One of the most abundant $N$-glycans $\left(\mathrm{Hex}_{3} \mathrm{HexNAc}_{6} \mathrm{dHex}\right)$ from these two glycoproteins is an asialo, core-fucosylated biantennary oligosaccharide with two GalNAc-GlcNAccontaining antennae [35,36]. Monosialylated $N$-glycans,

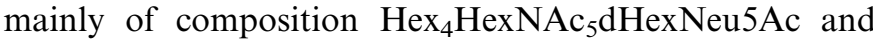
$\mathrm{Hex}_{3} \mathrm{HexNAc}_{6} \mathrm{dHexNeu} 5 \mathrm{Ac}$, are also present, with Neu5Ac but not Neu5Gc, terminating the antennae. Several other glycoproteins from bovine milk have also been reported to contain the GalNAc-GlcNAc epitope [37,38].

Attachment of GalNAc to GlcNAc has been thought to be controlled by an $N$-acetylgalactosaminyltransferase acting in competition with a $\beta 1$,4-galactosyltransferase on terminal GlcNAc-containing oligosaccharides [38,39]. Even though no glycan-dependent function has been reported for the GalNAc-GlcNAc non-reducing terminals present in bovine milk glycoproteins, it has been postulated that the occurrence of such structures in milk is associated with high $\alpha$-lactalbumin concentrations during the lactation. This protein is responsible for lactose biosynthesis and regulates the use of UDP-GalNAc by bovine milk $\beta 1,4$-galactosyltransferase in transferring GalNAc to biantennary acceptor glycopeptides [40]. Additionally, an $N$-acetylgalactosaminyltransferase, which transfers GalNAc from UDP-GalNAc to $N$-glycan chains ending in GlcNAc and responsive to $\alpha$-lactalbumin in lactating bovine mammary gland, has been described [41].

Koles et al. [5,42] recently studied the glycosylation and influence of lactation parameters of recombinant human $\mathrm{C} 1$ inhibitor (rhC1INH) expressed in the milk of transgenic rabbits. A broad repertoire of $N$-glycans, consisting of high-mannose, hybrid and complex-type oligosaccharides was reported. Complex-type $N$-glycans predominate, mostly monosialylated, core- $\alpha 1,6$-fucosylated and/or outer-arm $\alpha 1,3$-fucosylation (Lewis X). Sialylation level decreased with the progress of lactation independent of glycoprotein expression levels in accordance with earlier data reported for a few native human and bovine milk glycoproteins $[43,44]$. Recombinant preparations of human anti-thrombin expressed in the milk of transgenic goats have been reported by Edmunds et al. [6] and Zhou et al. [45] to contain GalNAc-GlcNAc epitopes and to show variable relationships between protein expression and glycosylation. Goats expressing high levels of hAnti-thrombin $(12.5 \mathrm{~g} / \mathrm{L})$ showed less heterogeneity in the $N$-glycan profiles than animals with low levels of expression. In those with high expression the most abundant species was the monosialylated core-fucosylated biantennary $N$-glycans with low amounts of Neu5Gc and GalNAc, whereas low expressing animals $(0.09 \mathrm{~g} / \mathrm{L})$ showed increased amounts of these two monosaccharides. Moreover, induced lactation decreased the amount of monosialylated $N$-glycans containing Neu5Gc, fucosylated biantennary with one GalNAc substitution on galactose. All these features probably account for the absence or very low abundance of high-mannose $N$-glycans, the high level of GalNAc compared to galactose and the equal amounts of Neu5Ac and Neu5Gc in our preparation of rhEPO expressed in goat milk at a level of $2 \mathrm{~g} / \mathrm{L}$.

Interesting was the quite different picture observed earlier when expressing hEPO in the mammary gland epithelial cells cultured in vitro [21]. Glycans in this system were mainly multiantennary complex oligosaccharides having Gal-GlcNAc and GalNAc-GlcNAc terminating antennae, with a high degree of core- and antennae-fucosylation together with $\alpha 1,3-$ Gal-Gal terminal units. Most of the charged $\mathrm{N}$-glycans were monosialylated with Neu5Ac with minor amounts of Neu5Gc. Thus, the mammary gland epithelial cells cultured in vitro efficiently assemble multiantennary $N$-glycans and sialylate them only with Neu5Ac. The difference in glycosylation observed in the milk is likely to be due to changes in the regulation of the glycosidases/glycosyltransferases during lactation, corroborating the celltype and environment glycosylation dependence.

In conclusion, therefore, it could be assumed that when the mammary gland secretes a protein into the milk the final glycosylation is dependent on the regulation of its glycosidases/glycosyltransferases enzymatic activities during lactation that inhibit the synthesis of multiantennary $N$-glycans, a property that seems to be shared by different species such as rabbits and goats, regardless of the protein which is being synthesized, the number of potential glycosylation sites or the glycosylation pattern in its native host. These aspects were confirmed by the similarities in $\mathrm{N}$-glycosylation patterns of the recombinant forms of $\mathrm{C} 1$ inhibitor (rabbit), human anti-Thrombin (goat), and human EPO (goat). The glycosylation processing similarities were even more apparent within the same species as illustrated with recombinant anti-thrombin and EPO in goat milk.

\section{Acknowledgments}

R.M., J.R.T., O.S. and J.A.C. were supported by collaborative projects from the Animal Biotech Division and the Biomedical Research Direction of the Center for Genetic Engineering and Biotechnology, Havana, Cuba. J.A.C. is also grateful to the Royal Society for providing funds for a study visit to the Oxford Glycobiology Institute. J.A.C., R.M., G.J.G. and J.P.K. are grateful to the Mizutani Foundation for Glycoscience for providing partial support to this work. We also thank the Wellcome Trust and the Biotechnology and Biological Sciences Research Council for equipment grants to purchase the Q-Tof and TofSpec mass spectrometers, respectively.

\section{References}

[1] H. Niemann, W. Kues, J.W. Carnwath, Rev. Sci. Tech. 24 (2005) 285-298.

[2] J.H. Nuijens, P.H.C. van Berkel, M.E.J. Geerts, P.P. Hartevelt, H.A. de Boer, H.A. van Veen, F.R. Pieper, J. Biol. Chem. 272 (1997) 8802-8807.

[3] P.H.C. Van Berkel, M.M. Welling, M. Geerts, H.A. van Veen, B. Ravensbergen, M. Salaheddine, E.K.J. Pauwels, F. Pieper, J.H. Nuijens, P.H. Nibbering, Nat. Biotechnol. 20 (2002) 484-487. 
[4] M. Massoud, R. Bischoff, W. Dalemans, H. Pointu, J. Attal, H. Schultz, D. Clesse, M.G. Stinnakre, A. Pavirani, L.M. Houdebine, J. Biotechnol. 18 (1991) 193-203.

[5] K. Koles, P.H.C. van Berkel, F.R. Pieper, J.H. Nuijens, M.L.M. Mannesse, J.F.G. Vliegenthart, J.P. Kamerling, Glycobiology 14 (2004) 51-64.

[6] T. Edmunds, S.M. van Patten, J. Pollock, E. Hanson, R. Bernasconi, E. Higgins, P. Manavalan, C. Ziomek, H. Meade, J.M. McPherson, E.S. Cole, Blood 91 (1998) 4561-4571.

[7] J. Denman, M. Hayes, C. O’Day, T. Edmunds, C. Bartlett, S. Hirani, K.M. Ebert, K. Gordon, J.M. McPherson, Biotechnology 9 (1991) 839-843.

[8] K.M. Ebert, P. DiTullio, C.A. Barry, J.E. Chindler, S.L. Ayres, T.E. Smith, L.J. Pellerin, H.M. Meade, J. Denman, B. Roberts, Biotechnology 12 (1994) 699-702.

[9] R.K. Paleyanda, W.H. Velander, T.K. Lee, D.H. Scandella, F.C. Gwazdauskas, J.W. Knight, L.W. Hoyer, W.N. Drohan, H. Lubon, Nat. Biotechnol. 15 (1997) 971-975.

[10] K.E. Van Cott, H. Lubon, F.C. Gwazdauskas, J. Knight, W.N. Drohan, W.H. Velander, Transgenic Res. 10 (2001) 43-51.

[11] A.G.A. Bijvoet, M.A. Kroos, F.R. Pieper, H.A. de Boer, A.J.J. Reuser, A.T. van der Ploeg, M.P. Verbeet, Biochim. Biophys. Acta 1308 (1996) 93-96.

[12] E.C. Visser, R. Dijkstra, J.P.J. Brakenhoff, E.J.J.M. van Corven, P.H.C. van Berkel, Glycobiology 10 (2000) 1133.

[13] M. Massoud, J. Attal, D. Thepot, H. Pointu, M.G. Stinnakre, M.C. Theron, L.M. Houdebine, Reprod. Nutr. Dev. 36 (1996) 555-563.

[14] J.-K. Park, Y.-K. Lee, P. Lee, H.-J. Chung, S. Kim, H.-G. Lee, M.-K. Seo, J.-H. Han, C.-G. Park, H.-T. Kim, Y.-K. Kim, K.-S. Min, J.-H. Kim, H.-T. Lee, W.-K. Chang, J. Biotechnol. 122 (2006) 362-371.

[15] C.T. Yuen, P.L. Storring, R.J. Tiplady, M. Izquierdo, R. Wait, C.K. Gee, P. Gerson, P. Lloyd, J.A. Cremata, Br. J. Haematol. 121 (2003) 511-526.

[16] T. Misaizu, S. Matsuki, T.W. Strickland, M. Takeuchi, A. Kobata, S. Takasaki, Blood 86 (1995) 4097-4104.

[17] K. Jacobs, C. Shoemaker, R. Rudersdorf, S.D. Neill, R.J. Kaufman, A. Mufson, J. Seehra, S.S. Jones, R. Hewick, E.F. Fritsch, Nature 313 (1985) 806-810.

[18] F.K. Lin, S. Suggs, C.H. Lin, J.K. Browne, R. Smalling, J.C. Egrie, K.K. Chen, G.M. Fox, F. Martin, Z. Stabinsky, S.M. Badrawi, P.H. Lai, E. Goldwasser, Proc. Natl. Acad. Sci. USA 82 (1985) 75807584.

[19] J.R. Toledo, O. Sánchez, R. Montesino, Y. Fernández, M.P. Rodríguez, J.A. Cremata, Biochim. Biophys. Acta 1726 (2005) 4856.

[20] J. R Toledo, O. Sanchez, R. Montesino, G. García, M. Montañez, P. Zamora, M.P. Rodríguez, J.A. Cremata, J. Biotechnol. 123 (2006) 225-235.
[21] O. Sánchez, R. Montesino, J.R. Toledo, E. Rodríguez, D. Diaz, L. Royle, P.M. Rudd, R.A. Dwek, G.J. Gerwig, J.P. Kamerling, D.J. Harvey, J.A. Cremata, Arch. Biochem Biophys. 464 (2007) 322-334. [22] U.K. Laemmli, Nature 227 (1970) 680-685.

[23] C.T. Yuen, C. Gee, C. Jones, Biomed. Chromatogr. 16 (2002) $247-$ 254.

[24] D.J. Harvey, J. Mass Spectrom. 40 (2005) 642-653.

[25] B. Domon, C.E. Costello, Glycoconj. J. 5 (1988) 397-409.

[26] E. Tsuda, M. Goto, A. Murakami, K. Akai, M. Ueda, G. Kawanishi, N. Takahashi, R. Sazaki, H. Chiba, H. Ishihara, M. Mori, S. Tejima, S. Endo, Y. Arata, Biochemistry 27 (1988) 5646-5654.

[27] M. Takeuchi, S. Takasaki, H. Miyazaki, T. Kato, S. Hoshi, N. Kochibe, A. Kobata, J. Biol. Chem. 263 (1988) 3657-3663.

[28] N. Inoue, M. Takeuchi, K. Asano, R. Shimizu, S. Takasaki, A. Kobata, Arch. Biochem. Biophys. 301 (1993) 375-378.

[29] C.H. Hokke, A.A. Bergwerff, G.W.K. van Dedem, J.P. Kamerling, J.F.G. Vliegenthart, Eur. J. Biochem. 228 (1995) 981-1008.

[30] H. Sasaki, B. Bothner, A. Dell, M. Fukuda, J. Biol. Chem. 262 (1987) 12059-12076.

[31] E. Watson, A. Bhide, H. van Halbeek, Glycobiology 4 (1994) $227-$ 237.

[32] D.E. Lee, B.J. Ha, S.J. Kim, J.S. Park, R.A. Yoo, M.S. Oh, H.S. Kim, J. Biochem. Mol. Biol. 29 (1996) 266-271.

[33] M. Nimtz, W. Martin, V. Wray, K.-D. Klöppel, J. Augustin, H.S. Conradt, Eur. J. Biochem. 213 (1993) 39-56.

[34] M. Nimtz, V. Wray, A. Rüdiger, H.S. Conradt, FEBS Lett. 365 (1995) 203-208.

[35] N. Nakata, K. Furukawa, D.E. Greenwalt, T. Sato, A. Kobata, Biochemistry 32 (1993) 4369-4383.

[36] C.A. Tilley, A. Singer, M. Harris-Brandts, M.A. Moscarello, Glycoconj. J. 8 (1991) 249-250.

[37] T. Sato, K. Furukawa, D.E. Greenwalt, A. Kobata, J. Biochem. (Tokyo) 114 (1993) 890-900.

[38] J.M. Girardet, G. Linden, J. Dairy Res. 63 (1996) 333-350.

[39] A.P. Neeleman, W.P.W. van der Knaap, D.H. van den Eijnden, Glycobiology 4 (1994) 641-651.

[40] K.-V. Do, S.-I. Do, R.D. Cummings, J. Biol. Chem. 270 (1995) 18447-18451.

[41] I.M. van den Nieuwenhof, W.E. Schiphorst, I. van Die, D.H. van den Eijnden, Glycobiology 9 (1999) 115-123.

[42] K. Koles, P.H.C. van Berkel, M.L.M. Mannesse, R. Zoetemelk, J.F.G. Vliegenthart, J.P. Kamerling, Glycobiology 14 (2004) 979-986.

[43] S.E. Carlson, Am. J. Clin. Nutr. 41 (1985) 720-726.

[44] E. Landberg, Y. Huang, M. Stromqvist, Y. Mechref, L. Hansson, A. Lundblad, M.V. Novotny, P. Pahlsson, Arch. Biochem. Biophys. 377 (2000) 246-254.

[45] Q. Zhou, J. Kyazike, Y. Echelard, H.M. Meade, E. Higgins, E.S. Cole, T. Edmunds. J. Biotechnol. 117 (2005) 57-72. 